\title{
Genetic privacy: orthodoxy or oxymoron?
}

\author{
Ann Sommerville and Veronica English British Medical Association, London
}

\begin{abstract}
In this paper we question whether the concept of "genetic privacy" is a contradiction in terms. And, if so, whether the implications of such a conclusion inevitably impact on how society comes to perceive privacy and responsibility generally. Current law and ethical discourse place a high value on self-determination and the rights of individuals. In the medical sphere, the recognition of patient "rights" has resulted in health professionals being given clear duties of candour and frankness. Dilemmas arise, however, when patients decline to know relevant information or, knowing it, refuse to share it with others who may also need to know. This paper considers the notions of interconnectedness and responsibility to others which are brought to the fore in the genetic sphere and which challenge the primacy afforded to personal autonomy. It also explores the extent to which an individual's perceived moral obligations can or should be enforced.
\end{abstract}

(Fournal of Medical Ethics 1999;25:144-150)

Keywords: Genetics; ethics; genetic privacy; confidentiality; duty to know

\section{Autonomy rules?}

In Britain, as in many industrialised societies, current law and ethical discourse coincide in placing a high value on personal self-determination. Both law and ethics recognise the rights of citizens to make even apparently irrational or self-damaging decisions. Such choices can generally only be overridden when they demonstrably harm others. Unless they fall within the statutory definition of "mental disorder", adults cannot be obliged to accept any diagnostic test or treatment. Their right to refuse procedures which would give them information or benefit their health is unambiguous. "The general principle of English law is that patients are the best judges of what is good for them, and it is firmly set against paternalistic interference with autonomy."'

If provision of health care is patient-centred, it is also centred on individual patient choice. Increasingly, this is not a question of responding uncritically to "need" but rather a matter of adjusting what is on offer to individual patients' wants and values. Questionnaires and other methods of evaluating patients' response to care pack- ages attempt to ensure that people get what they want, rather than what others consider th should have, from health services. The General Medical Council (GMC) exhorts doctors to "li $\mathrm{l}^{\omega}$ ten to patients and respect their views" as a co element of good medical practice ${ }^{2}$.

People have a recognised entitlement to be self ish in their choices. Clearly articulated rules about helping others do not feature in our national cols sciousness, except for people who have a contra 9 tual or professional obligation to care. Courts reiterate the absence of any duty to donate blo or tissue, even to close relatives where a goot match might be likely. Pregnant women can refus $\vec{\theta}$ interventions in labour to save a viable fetus. Pe $\oplus$ ple losing their mental abilities can make legalty binding advance refusals of treatment, removing from relatives or carers any say on their behalf. inescapable conclusion from all this is that peop are primarily responsible for themselves alon $\mathbb{E}$. While acknowledging the importance of famili $\overrightarrow{g s}$ to societal stability and personal satisfaction, sockety also apparently accepts that families can of out of caring for each other, including for their dependent or disabled members. Nevertheless, 骨 a time when pundits and politicians bemoan the disintegration of family life, two trends seem to against this tide. One is the rapid development of genetic technology, reawakening awareness of the practical importance of familial links. The other $\dot{\phi}$ the development of the communitarian ethis, emphasising mutual inter-dependence and pringe ples of responsibility for others.

Although genetics may not raise intrinsicalPy new dilemmas about patient confidentiality, fit adds an extra resonance to problems arising from an individual's refusal to know or to sha information. Developments in genetics have led a greater understanding of the inter-relatedness off individuals and the way in which the interests of one family member cannot be entirely isolateg from the interests of others. Because of share DNA, one person's susceptibility to a genetic dif order means that other blood relatives will also be at risk of developing that disorder. An individuaks awareness of being a carrier of a genetic disord8r alerts her to the fact that the same risks apply her siblings. A woman who has a son with Duc- 
enne Muscular Dystrophy and has tested positive for carrier status, for example, has information which is clearly relevant to her sister in planning her own family. In such circumstances, few decisions are entirely personal.

Human genetics is concerned with direct biological relationships and the transmission of certain traits or susceptibilities within families. The family is also at the core of communitarian concepts of mutuality, responsibility for others and inter-dependence. These challenge the importance accorded to personal rights, by centring the interests of individuals within the context of various networks of relationships. Because of the manner in which it takes into account the impact individuals' choices have on those close to them and on the community, communitarianism seems particularly appropriate to the debate about genetics. In an extreme form, however, it can be as unhelpful as an extreme preoccupation with individual rights to the exclusion of other considerations.

At its most extreme, communitarianism undermines personal liberty and permits the sacrifice of individuals in order to attain communal goals. Modified to allow a balance between individual and group interests, however, communitarianism may assist in the search for a fair compromise between genetic privacy and the need of others to know facts germane to their own wellbeing. In its discussion of ethical frameworks within which to conduct the genetics debate, the British Medical Association (BMA) has perceived a usefulness in communitarian precepts and "a value in discussing how decisions can be made in ways which reflect social and cultural contexts". ${ }^{3}$ While acknowledging that this has particular relevance to genetics, the BMA goes on to emphasise that "All patients' decisions, not only those in the genetic context, should take account of serious implications for others". ${ }^{4}$ This implies that society may need to reassess the apparent pre-eminence accorded to privacy and personal autonomy generally. If people are seen to have moral duties to close relatives and those they bring into the world, this raises difficult questions in relation, for example, to a woman's right to refuse caesarean section when the result will predictably be damage to her viable fetus as well as possibly her own death, depriving her existing children of a mother.

\section{Rights and responsibilities}

Although perhaps unrepresentative of how most people make decisions in real life, the autonomous individual is a paradigm featured in many legal and ethical guidelines. Apparently unconstrained by social or emotional claims made by others, the autonomous person defines his own best interests and acts accordingly. In much of the literature, his sole interaction is seen as with his doctor rather than with people close to him who will be affected by his decisions. Meyer, for example, in an article discussing patients' duties, sees these solely in terms of the individual's duty to himself ("the duty to engage in responsible self-care" and to "make responsible decisions about his own self-care") and to his doctor. "The autonomous patient - capable of and inclined toward selfdirection by way of rational deliberation - is engaged in a cooperative partnership with the autonomous health care professional". "Meyer admits, however, that the whole issue of patients' duties is one that is "out of fashion" and "has received little attention".

This is not to say that we lack a body of literature concerned with concepts of duty and responsibility. In medicine, however, discussion of duty has been traditionally confined to the role of health professionals who, unlike others, can be obliged to fulfil their acknowledged duties. Among these, are the obligations to provide information and counsel patients in a non-directive manner, allowing them to make their own choices. Arguments about patients' obligations have only seemed to attract attention in relation to such issues as those raised above by Meyer. In the UK, there has been media debate about a patient's duty to cooperate with ongoing therapy, for example, by stopping smoking or drinking when such habits jeopardise surgery. Other duties, such as the notion of a duty for patients to participate in medical research or medical training has generally received short shrift and the unpressured voluntariness of such altruistic activities is emphasised.

Given that we lack any developed concept of patient duties, it is understandable that much of the ethical analysis in relation to the very sensitive issues arising in fertility, reproduction and genetics, focuses on patient rights rather than duties. Significant issues for debate have concerned the right to have children or to access fertility treatment. The reluctance to speak about patients' duties in terms of reproduction and genetics is compounded by the heritage of the eugenics movement. Arguably, however, with increasing awareness of the genetic components of illness and behaviour patterns within families, we have already begun to see a shift in emphasis away from the individual and personal autonomy. Replacing this is greater recognition of the need for a more communitarian approach, taking account not only of rights but of corresponding duties to others.

"Rights" and duties" are usually seen as complementary: each right imposing a corre- 
sponding duty on someone else. Both are social constructs and, ideally, society should avoid establishing mutually contradictory rights and duties. As Rhodes points out "in the case of genetic knowledge this use of the terms 'right' and 'duty' makes it clear that if someone has a right to genetic ignorance, he has no duty to pursue genetic knowledge, and if someone has an obligation to pursue genetic knowledge, she has no right to preserve her genetic ignorance". ${ }^{5}$ In practice, however, the situation is less clear. Relatives' "right" to test their own genetic make-up may well also reveal to them, by implication, the health status of the family member who refused the test and who has a "right" to ignorance and privacy. Among the many complex issues raised by genetic technology is this tension between the apparently legitimate but contradictory rights of different people.

\section{"Harm" and risk}

Medical ethics, of course, has always had to develop mechanisms for dealing with such conflict and one way of doing that is to seek the solution which minimises harm and maximises benefit - ie a consequentialist solution. Health professionals have long been accustomed to this type of reasoning, which frequently requires them, as the detached outsiders, to make a judgment about whether a breach of confidentiality is justified. The main difference with communitarianism is that it unambiguously focuses responsibility on the main players - patients themselves - making them explicitly holders of duties (normally reserved for health professionals) rather than just holders of entitlements. It is their own special interconnectedness with others - either through shared DNA or a shared commitment to having children - which provides the moral underpinning. They may, of course, hate their siblings and feel no obligation to the family. They may simply not care about the harms others face. In which case, by default, the traditional consequentialist argument may well return the duty to the outsider - the health professional - to decide which harm is the lesser. Our suggestion is not, therefore, that a communitarian perspective should supersede other frameworks but, that as an add-on to traditional ways of thinking, it potentially offers some advantages in raising individuals' awareness of a duty to consider others and take responsibility for harms that arise from their own choices.

But how should "harm" be weighed in these circumstances? It can be argued that an unwanted revelation of distressing information constitutes a "harm" to the recipient. It might, however, be harmful to collude with that person's reluctance to know if that jeopardises the ability of other individuals to gain data about themselves. At tempting to establish a hierarchy of different degrees and types of harm in order to choose the lesser is obviously difficult, if not impossible.

Dickenson $^{6}$ suggests one potentially usefut parameter in terms of risk management. In th context of discussing the rights of affecte individuals to have children without accessing information about the extent of their own susceptibility to the genetic disorder, she suggests "we might concentrate on the degree of risk involved" She points out that although many of the othes factors one would want to consider, such as the rights claims of the various parties do not readiliso admit of quantification and compromise, ris management does. "Genetic disorders with a high" probability of transmission, in this view, are more 'wrong' to disregard than those which pose only 8 small risk". Nevertheless, she concludes that although a father who refuses genetic screening knowing himself to have a fifty per cent risk of inheriting Huntington's disease is acting unethiु cally, health professionals have no right or duty t\$ pressurise him to act more altruistically. We maף well consider that individuals have moral obligas tions to reduce the risks and harms for other close to them when they have the possibility to de so. The issue of whether this can be enforced something we consider later in this paper.

\section{To know or not to know?}

Health information is important in different ways: It can be a potent aid in empowering patients t⿹ make valid decisions about their treatment of non-treatment options. In the provision of care to competent people - whether adults or minors $\dot{8}$ encouraging informed patient consent is a fundac mental aspect of good practice. It is generalls assumed to be desirable for people to be aware of their own health status and the implications of the both for themselves and for others affected bib their decisions. Access to appropriate information is perceived as a "right" which health professions als are bound to observe. "Give information t⿳亠丷厂 patients in a way they can understand" an "respect the right of patients to be fully involved io decisions about their care" advises the Gener. Medical Council. ${ }^{7}$ But can receiving information also be an obligation for patients? Does the healt professionals' duty to deliver information imp市 patients will be given it whether or not they wan it?

Common sense and respect for individuats would appear to support the concept that peopl 8 need not necessarily have information they do no want. From a legal perspective, there seems tô. 
have been little debate about this issue although Kennedy and Grubb discuss whether legally "a patient may (expressly or impliedly) absolve a doctor from his duty to inform, assuming the situation to be one in which this duty prima facie exists". They conclude that the "answer is probably sometimes but not always. Regrettably it is difficult to be much more precise than this." ${ }^{8}$ In the United States, one authoritative view concerning the provision of information in relation to diagnosis and treatment is that:

\begin{abstract}
"The legal requirements for effective waiver in the context of informed consent have never been clearly articulated by the courts. There is substantial reason to believe that the courts would respect waivers of certain information ... or the delegation of certain decisions to others. Yet it is questionable whether patients should be permitted to waive the professional's obligation to disclose fundamental information about the nature and implications of certain procedures. ... In the absence of explicit legal guidance, health care professionals should be quite circumspect about allowing or disallowing, encouraging or discouraging, a patient's use of waiver."
\end{abstract}

While this caveat presumably applies to information relevant to a specific treatment, would it also apply to a reluctance to know one's general health status? Should health professionals be more circumspect in accepting a person's refusal to know important health information and more active in encouraging patients to access knowledge? In general, it seems, we believe knowledge to be a good thing but do different rules apply if the information concerns the inevitability of an untreatable, degenerative condition? We note elsewhere in this paper, for example, the low uptake of presymptomatic testing for Huntington's disease which is partly attributable to the fact that people prefer not to know about a condition they cannot alter. If this concept were applied to other cases, paternalistic doctors might be correct in concealing the fact of a terminal illness when there is no action a patient could take to postpone or somehow ameliorate that prospect. In the context of fatal illness, however, it is recognised that the individual's right to know should prevail, partly because people have other goals in life than just managing their health. Foreknowledge of an inevitable disease permits them to plan for those other goals and, potentially, to prepare people close to them for the inevitable changes in their lives.

People have different ways of coping with harmful or threatening information. Some re- spond by wanting to learn as much as possible about the disorder, seeking whatever advice is available and seeking testing. Others though, may take the opposite route, trying to ignore the issue, refusing to discuss it and refusing to find out more information or to seek testing. ${ }^{10}$ Denial is a common defence mechanism. With the latter group, the harm to the individual of removing that coping strategy needs to be recognised. Does the innate tendency to protect oneself from harmful knowledge override any duty towards others?

\section{Duties to others: blood is thicker than water}

If a "duty to know" exists, to whom is it owed? One can envisage the possibility of an obligation to others to alert them to information about predictable future events which will profoundly affect them. The old saying "blood is thicker than water" implies that blood relatives are owed the greatest duties and loyalty. Intuition may appear to support this conclusion. This response may be based as much on an awareness of how blood relatives have a shared history and social involvement as on the importance of shared genes. Commentators have explored the notion of special duties owed within special types of relationships. Rhodes argues that blood ties are not necessarily the basis of people's ethical responsibilities to one another. She says:

"If genetic similarity were the source of our moral relationships, genetic maps could identify our most similar sibling, or even some distant DNA matching stranger, as the one to whom we owed the most. But if anyone maintained that we had different degrees of responsibilities to different siblings it is not likely that they would attribute that distinction to our degrees of genetic matching. More likely reasons would be related to the intimacy and dependency of our previous relationship, or the strength of our feelings, or the history of our interactions, or something about our relative wherewithal and neediness." 5

But it is not only those who are genetically related who may have a valid and important reason for wanting to know about another's genetic heritage. If a couple are planning to have children, for example, the man has a legitimate interest in knowing whether the mother of his potential child is a carrier of a serious $x$-linked condition. If genetic abnormalities have been detected in either family, it would be important to know if either partner were likely to develop a disabling genetic disorder. Each partner may prefer to remain ignorant of his or her own genetic status but if the technology exists to give an accurate picture, 
might there not be an obligation to access knowledge for the sake of others - not least for the wellbeing of the potential child? If the condition is a dominant, late-onset disorder, a preference for ignorance may mean that many children are born at risk of the condition before it manifests itself in a parent. The issues arising here concern not only the obvious debate about affected individuals' rights to have children and the risks of transmitting mutations to future generations but also the acceptability of depriving another person of the opportunity to make an informed decision about having a family.

It has been argued that special duties arise when people make a commitment to one other such as in an intimate relationship, marriage, or creating children. Such commitments carry moral responsibilities. Dickenson argues that an individual's duty to know and share genetic information with partners is based on this "duty of entering into a relationship" rather than on "rights" or issues of risk assessment. ${ }^{6} \mathrm{~A}$ similar conclusion is reached by Rhodes who says "when we have to decide whether to assume an obligation and when the decision even in part turns on genetic knowledge, we have a moral duty to pursue that information". ${ }^{5}$

\section{Duty to oneself?}

It might also be argued that people owe it to themselves to make well-informed decisions. This is the core of Meyer's argument quoted previously. $\mathrm{He}$ postulates a duty which includes being well informed and actively involved in one's own health care by making rational decisions about it. He suggests that:

" the autonomous patient has a duty to avoid being a patient. The root meaning of 'patient' is 'a person or thing that undergoes some action'. Literally a patient is the conceptual opposite of an agent, the person who bears responsibility for his actions."4

It has been argued that the duty to know certain information stems partly from an obligation to exercise one's own autonomy properly. Discussing autonomy from a Kantian perspective, Rhodes says:

"The core content of my duty is selfdetermination. ... I need to appreciate that my ethical obligation is to rule myself, that is, to be a just ruler over my own actions. ... When I recognise that I am ethically required to be autonomous, I must also see that, since autonomous action requires being informed of what a reasonable person would want to know under the circumstances, I am ethically required to informed."

She goes on to discuss genetic information in pa䲩 ticular, stating:

"if I have an obligation to learn what I can whe genetic information is likely to make a significa difference in my decisions and when the info हैmation is obtainable with reasonable effort, I have no right to remain ignorant. From the recognitio of my own autonomy, I have a duty to be informed". 5

To most of us this is an unfamiliar argume䨛 except perhaps in terms of having an obligation $t 0$ ourselves to make the "right" decision in our own circumstances. In many situations, we can only do this with access to the information which cough help avert or palliate some evil. One of the difficulties with genetic information, however, that it can reveal some dire future prospect which cannot be averted or postponed because no effe $\overrightarrow{\varepsilon_{0}}$ tive treatment exists for the predicted condition $\biguplus$

The assumption that it is generally better know than not to know one's genetic heritage widespread among both health professionals ant patients. The Genetic Interest Group, a suppogt group for families with genetic disorders, states one of its publications: "the primary presumption that underpins professional practice can be simp $\$$ stated: it is better for individuals to be informed of their genetic risk than not to be so informed" The low uptake rate of presymptomatic testing fr Huntington's disease, estimated at $10-20 \% \S^{2}$ however, can be seen to challenge this, at least from the perspective of those most affected. must be acknowledged that Huntington's disease raises specific issues and is atypical of genetic testing since nothing can be done to ameliorate the course of the disease. Nevertheless, these data ard studies of the uptake of testing for other disorde indicate that a large proportion of the population at risk do not wish to know their genetic status. view of the relevance of the information to othetws the question arises of whether they are moralby entitled to make this decision.

It could be argued that there is a significant d $\mathrm{d}$ ference between requiring individuals to obtain information which is not already available andel requiring them to share existing information. If they have shared the information of being at risk with those for whom it has personal relevanoe perhaps they should be seen to have fulfilled their moral obligations to others, if not to themselves. If the woman who has a child with Duchenne Mucular Dystrophy has not had a test for carrier 
tus, would she be morally obliged to do so? She would, arguably, be fulfilling any moral obligations to her sister by informing her that she could be a carrier of the condition and that her sister might wish to seek advice before planning her family. She would not, however, have fulfilled any obligation to herself in terms of her "duty to be informed" in order to make autonomous decisions. There must come a stage, however, where the pressures of obtaining information become so onerous that the duty to protect oneself from harm becomes the higher priority. Thus, the greater moral obligation might be to share existing information rather than to obtain information which is not already known. A refusal to share existing information, where that decision leaves others open to avoidable and serious harm, raises the inevitable question of the extent to which one is morally entitled to make selfish decisions.

\section{Can genetic information be exclusively owned?}

When genetic information is revealed about one individual it often releases information about others. One person's right to genetic privacy and medical confidentiality conflicts with the rights of siblings or other relatives to have the knowledge that would permit them to exercise a right of choice. As soon as one has information about one's own genetic heritage, information about relatives can usually be inferred. This interconnectedness of interests has led some commentators to suggest that the "patient" should be seen as the family rather than any particular individual. The Royal College of Physicians, for example, suggests that:

"because of the nature of genes, it may be argued that genetic information about any individual should not be regarded as personal to that individual, but as the common property of other people who may share those genes, and who need the information in order to find out their own genetic constitution. If so, an individual's prima facie right to confidentiality and privacy might be regarded as overridden by the rights of others to have access to information about themselves". ${ }^{13}$

This presumes that responsibilities are shared by individuals who share the same genes. As we have argued, above, however, information is not only relevant to relatives but also to people with whom affected individuals form emotional relationships and have children. Nevertheless, the fact that we may assign moral obligations in such circumstances does not necessarily entail the enforcement of those duties.

\section{Can moral behaviour be enforced?}

Most people, once aware of the implications of genetic information for other people, willingly share the information with those for whom it has special significance, but what of those who refuse to share information? Should they be obliged to do so? If, despite being informed of the implications of the information for others, whether siblings or partners, the individual refuses to disclose it, doctors are faced with a conflict between their duty of confidentiality to their patient and a wider duty to protect others from avoidable harm and suffering. If both parties are the doctor's patients and are each owed a duty of care, this conflict appears more acute.

Confidentiality is one of the cornerstones of medical practice but it is not an absolute duty. The General Medical Council states that disclosure "may be necessary in the public interest where a failure to disclose information may expose the patient, or others, to risk of death or serious harm". ${ }^{14}$ Making judgments about whether breaches of confidentiality are justified in particular circumstances presents doctors with difficult dilemmas, but this is not exclusive to genetics. It is also part of a doctor's duty to make these judgments in other spheres - whether to breach confidentiality when a serious crime has been committed, for example, or where there is a suspicion of abuse of a vulnerable person or where an individual with a serious communicable disease is putting others at risk. It is accepted as good practice to forewarn individuals before breaching their confidentiality. If this is likely to arise in a situation where someone is considering undergoing testing, it should be brought to his attention in advance as a factor he should consider. He may decide not to proceed with testing, as an informed choice.

It could be argued that there is a difference between breaching confidentiality in order to avoid a serious harm, such as when a vulnerable person is being abused, and breaching confidentiality in order to provide a benefit, such as to allow a relative to make informed choices. Our society has steadfastly resisted recognising a duty to benefit others while acknowledging an obligation not to harm them. We must be aware of the possibility that communitarian arguments could introduce such a duty through the back door. This distinction, however, depends upon a, perhaps, artificial distinction between duties concerning harms and benefits; certainly in many circumstances a failure to benefit could constitute serious harm. Whether the "serious harm" to be avoided is sufficiently grave to fulfil the criteria set out by the GMC will depend on the individual circumstances and is likely to depend upon factors such 
as the severity of the disorder, the level of predictability of the information provided by testing and what, if any, action the relatives could take to protect themselves or to make informed reproductive decisions, if they were told of the risk. These factors need to be balanced against the potential risks of undermining the duty of confidentiality, which could deter individuals from seeking genetic testing but could also have a damaging effect, more generally, on the doctor-patient relationship.

\section{Conclusion}

Although not new, the dilemmas around respecting a choice not to know or not to share information receive a new slant through genetics. Interconnectedness and responsibility to others are brought to the fore in the genetic sphere in a manner which seems to run counter to current ethical and legal orthodoxy. Extreme notions of individual rights and autonomy are insufficient to deal with these complex and interwoven interests. A more useful framework is gained by combining notions of autonomy with a modified version of communitarianism which recognises that decisions made by one person inevitably affect others and that an individual cannot have rights without also accepting that he or she has certain duties. The limit of these moral duties and the extent to which they could or should be enforced will depend upon the individual circumstances. In the genetic sphere, for example, hard questions arise about the moral acceptability of the individual's usual right of privacy. In the light of these, we may need to reconsider the scope of such a right, which would allow the withholding of information, which is indirectly about themselves, from people whose lives could be changed by it. Children or siblings may wish to access information about family histories - which arguably are the common heritage of them all - in making their reproductive decisions. The luxury of informed choice should not be exclusive to the individual in the family who, by luck or judgment, is the best informed about factors affecting all.
While the effect on others of an individua婴 refusal to know and share information is very prōnounced in genetics, it is not exclusive to this area of medicine. Other comparable health decisio also impact on others to whom we hame obligations. It may be that we need to reconsider general issues of personal privacy and duty spouses, partners or other family members.

\section{Disclaimer}

This paper reflects the personal views of the authors and does not necessarily reflect those if the British Medical Association.

Ann Sommerville is Head of Medical Ethics at the British Medical Association and Veronica English $\frac{15}{15}$ Deputy Head of Medical Ethics at the British Mescal Association.

\section{References}

1 Montgomery J. Health care law. Oxford: Oxford University Press, 1997: 47.

2 General Medical Council. Good medical practice. London: G eral Medical Council, 1998: para 12.

3 British Medical Association. Human genetics: choice and resp $\overrightarrow{\mathrm{H}^{t-}}$ sibility. Oxford: Oxford University Press, 1998: 25.

4 Meyer M. Patients' duties. The Fournal of Medicine Philosophy 1992;17:541-55.

5 Rhodes R. Genetic links, family ties and social bonds: rights and responsibilities in the face of genetic knowledge. The foxisnal of Medicine and Philosophy 1998;3:10-30.

6 Dickenson D. Carriers of genetic disorder and the right to haye children. Geneticae Medicae et Gemellologiae 1995;44;75-80.

7 See reference 2: para 11.

8 Kennedy I, Grubb A. Medical law: text with materials [2nd ed]. London: Butterworths, 1994: 232.

9 President's Commission for the Study of Ethical Problems $9 n$ Medicine and Biomedical and Behavioral Research. Makmg health care decisions. Washington: US Government Printighg Office, 1983 (quoted in reference 8).

10 Richards $M$. Families, kinship and genetics. In: Marteau $\mathcal{O}_{\Gamma}$, Richards M, eds. The troubled helix. Cambridge: Cambridge University Press, 1996: 266-7.

11 Genetic Interest Group. Confidentiality guidelines. Lond욤ำ Genetic Interest Group, 1998:10.

12 Bundey S. Few psychological consequences of presymptomamic testing for Huntington Disease. The Lancet 1997;349:4.

13 Royal College of Physicians. Ethical issues in clinical genetio. London: Royal College of Physicians, 1991: para 4.10. O

14 General Medical Council. Confidentiality. London: Genqral Medical Council, 1995: para 18. 